\title{
Três esboços de horizontes imprecisos - lentes de Allan Kaprow para pensar a performance hoje
}

NARDIM, Thaise Luciane ${ }^{1}$

Resumo:

A partir da obra de Allan Kaprow são propostas três lentes para pensar a arte da performance hoje: primeiramente, o entendimento dos happenings como uma forma inicial de teatro performativo; em seguida, a proposição da ausência como valor indissociável da presença em performance; por fim, o papel da brincadeira como modo de nutrir a vida e a arte.

\section{Palavras-chave:}

Allan Kaprow; Arte da Performance; Happening.

Abstract: From Allan Kaprow's work we propose three lenses to think the Performance Art today: first, the understanding of the happenings as an earty form of Performative Theater; then, the value of absence, something inseparable from the presence in performative practices; and finally, the role of childsplay as something to nurture life - and art.

Keywords: Allan Kaprow; Performance Art; Happening.
Performer e professora na Universidade Federal do Tocantins, no curso de Artes - Teatro. Mestre em Artes pela Universidade Estadual de Campinas. E-mail: thaise@uft.edu.br 
Na discussão sobre os antecedentes ou mesmo os disparadores do que hoje entendemos como arte da performance, a obra deixada pelo artista americano Jackson Pollock figura indubitavelmente. De modo geral, a interpretação oferecida pelos historiógrafos ou comentadores da história da arte da performance indica o gesto realizado pelo pintor, isto é, a ação de fazer/deixar gotejar e o desempenho corporal que ela implica, a inserção do corpo no campo da lona e a eventual abertura desse processo à visualização por um público atual ou virtual, tudo isso visto como a grande contribuição oferecida pelo pintor ao aparecimento da arte que, então, surgia nos Estados Unidos.

Allan Kaprow oferece uma leitura particularmente rica dessa qualidade pictórica que Pollock nos apresenta. Em seu artigo O legado de Jackson Pollock (KAPROW, 2006), redigido dois anos após a morte daquele pintor, Kaprow propõe-se a analisar as possibilidades que se colocavam para a arte a partir deste fato, tendo em vista que Pollock, ainda segundo Kaprow, já não vivia mais o auge de sua produção quando de sua morte.

Sem buscar fazê-lo, porém, o autor anuncia a influência da action painting sobre seu trabalho posterior, assim como ressalta outras características da produção de Pollock que, a partir de sua apresentação, podem ser lidas como germes pictóricos da performance como linguagem artística.

Para a construção que pretendemos aqui erigir, não são suas belas palavras sobre o gesto de Pollock, apresentados por ele como dança, gestos "quase absolutos" e liminares - no limite com o ritual - que nos interessam. Existe, especialmente, outra qualidade em Pollock, destacada por Kaprow, que não apenas constitui chave para a leitura do que viria a ser a linguagem performática, como também auxilia a entender aquilo que Kaprow passaria a promover logo após a redação deste texto, ainda em 1958, mas especialmente a partir de 1959, com 18 happenings in six parts - os primeiros happenings, seu novo teatro.

Esta qualidade, embora não anunciada nesses termos por Kaprow, é a dimensão energética da abstração promovida pelo expressionismo: não a energia que emana diretamente do encontro entre o corpo físico do artista e a matéria, mas o registro desse encontro, revelado em linhas, dinâmicas, dimensões e mesmo campos de cor e luminosidade ${ }^{2}$. Nesse sentido, Kaprow comenta a escala das obras de Pollock:
2.

As duas últimas características observam-se já não tanto em Pollock, mas, por exemplo, em Rothko. 
Diante de uma pintura, o nosso tamanho como espectadores, em relação ao tamanho da pintura, influencia profundamente nossa disposição a abrir mão da consciência de nossa existência temporal enquanto a experimentamos. A opção de Pollock por grandes formatos faz com que sejamos confrontados, tomados de assalto, absorvidos (KAPROW, 2006, p. 42).

O discurso de um espectador que se vê abordado pela obra, como se ela se impusesse sobre ele, é tema de diversos autores que se debruçaram sobre as obras do período. Como exemplo, Lyotard afirma que "A arte era suficientemente plena de alienação e ansiedade, e bastante expressiva da fragmentação violenta e da destruição criativa" (1998, p. 43). Também Clark (2007) comentou sobre essa força que emana de grande parcela das referidas obras ao avaliá-las como espécimes vulgares e conformar, assim, mais um registro desta dimensão carnal do abstracionismo por parte da crítica.

No que diz respeito à obra de Allan Kaprow, interessa não somente a dimensão evidente de sua relação com essa forma de pintar, já que, como sabemos, o artista foi também integrante do movimento expressionista e aluno de outros grandes pintores, mas pretendemos destacar o quanto desse entendimento está apresentado nos trabalhos que efetivamente fazem com que ele componha os anais da história da arte contemporânea - os happenings. Para isso, vamos pensar especialmente em 18 happenings in six parts, que exemplifica a contento aquilo que queremos observar.

Adicionalmente, pensaremos na produção dramatúrgica dos anos 1950, ou até eles: o teatro produzido até aquele momento, especialmente aquele que se revela ainda hoje, para nós, pela forma escrita ou por registros imagéticos. Quais são os níveis de abstração que esse teatro apresenta? Certamente, podemos observar uma determinada abstração em escritos do Teatro do Absurdo, que começa a se edificar exatamente naquele momento. A própria ideia de absurdo - que a crítica utiliza para nomear o realismo extremo dessas produções - parece, a princípio, identificar o que seria uma possibilidade de abstração no teatro. Isolado no tempo, em um momento que muito antecede a abstração na pintura ocidental, Alfred Jarry também pode ser compreendido como um abstracionista, com seu Ubu Rei de formas e fatos indeterminados e sem congruências.

Ambos os casos parecem-nos mais propícios a um paralelo com a abstração que a história da pintura chamou de abstracionismo gráfico - aquelas obras em que, distintamente do informal expressionista, linhas, traços, curvas e seus análogos, parece querer construir outra representação, uma nova linguagem que obedeça aos mesmos moldes da mimética ou da verbalidade, compondo, ao fim, formas. São formas as persona- 
gens que se apresentam, tanto em um como em outro de nossos exemplos. São formas os atos ou o recorte temporal que encaixotam o transcurso do espetáculo e o tornam assimilável à cultural teatral ocidental. São formas os diálogos, formas de troca intersubjetiva herdadas da tradição dramática, cumprindo essa mesma função, ainda que desconstruídas em sua sintaxe. Muito antes de nós, Michael Kirby observou tal aspecto que estamos explorando, ao tratar justamente do que ele anunciou como um "novo teatro":

A estrutura de informação do teatro tradicional não é alógica, mas ou lógica, ou ilógica. A informação é construída e interrelacionada tanto no jogo lógico da peça bem-feita como no sonho "ilógico", surreal, absurdo. O ilógico depende de uma consciência do que é o lógico. A estrutura alógica permanece completamente fora dessas relações ${ }^{3}$ (KIRBY, 1965, p. 28, tradução livre).

Um teatro informal - ou seja, um teatro não formalizado pela representação que a razão promove, um teatro pré-simbólico, que opera na freqüência das forças - é o que nos pede e nos insinua Antonin Artaud. Um teatro da "não forma", do pré-objeto, do tempo como temporalidade, em que se impõem as carnalidades e a materialidade primeiras da arte teatral, um correspondente cênico do que seria o abstracionismo informal na pintura: tal teatro é, em grande medida, aquele que chamamos hoje de teatro performativo, termo cunhado contemporaneamente. Porém, esse teatro já estava acontecendo em 1959, nos primeiros happenings de Allan Kaprow.

Nos happenings de Kaprow não existem personagens configurados. Em 18 happenings, os performers, amigos do artista, apenas executam tarefas, sem que esteja depositada sobre eles alguma matriz ou camada semântica que viria a engendrar a consolidação de outra pessoa, outra história, outra narrativa que não aquela que, por natureza, emite o corpo ali apresentado. Da mesma maneira, a dramaturgia de colagem de ações proposta pelo artista - neste caso, apresentando dezoito acontecimentos combinados em seis partes, cada qual composta por três acontecimentos sucessivos, mas sem relação de causalidade - compõe uma narrativa que impõe uma temporalidade diferenciada daquela que o espectador experimenta no teatro convencional, mesmo que a duração deste evento coincida com a do velho teatro.

Entender o happening inicial de Kaprow não mais como uma forma autônoma, mas sim em diálogo com a história das artes cênicas, constitui o fato de que, nos Estados Unidos, existiu um teatro performativo concomitante ao surgimento da própria arte da performance. Isso redireciona o olhar não apenas para a produção americana do início dos anos 1960, bem como pode possibilitar uma reinvenção do modo de contar a história do
3.

No original: "The information structure of traditional theatre is not alogical but either logical or illogical. Information is built and interrelated in both the logical well-made play and the "illogical" dream, surreal, or absurd play. Illogic depends upon an awareness of what is logical. Alogical structure stands completely outside of these relationships" (KIRBY, 1965, p. 28). 
teatro e, especialmente, de contar a história da arte da performance, eliminando de vez a celeuma que insiste e resiste em determinados discursos - por mais que a concretude dos fenômenos continue se apresentando de modo a desacreditá-la -, em que origens e fazeres performáticos de via teatral e de via plástica são distinguidos, tomados como apartados.

\section{Performances da presença-ausência}

TORNAR-SE INVISÍVEL

a) por esconder-se

b) pela retirada de todas as marcas que o identificam

c) por ir embora

d) por afundar no chão

e) por tornar-se outra pessoa

f) por concentrar-se tanto em algum objeto ou idéia que você deixa de estar consciente do sua presença física físico.

g) por distrair todo mundo de sua presença física

h) por deixar de existir4 (FRIEDMAN, 2002, tradução livre).

Allan Kaprow foi, ao longo do trajeto construído a partir de meados dos anos de 1960, um artista a velar-se: ocultou(-se) das instituições que caracterizam o sistema de arte - a galeria, a mídia; ocultou(-se) e deixou desaparecer do registro a obra; ocultou(-se) em/de sua própria obra e, por fim, ocultou(-se) do "ser artista" enquanto categoria profissional em absoluto.

Ele mesmo, atuando como protótipo de suas proposições, Allan Kaprow - an-artista - está, mas não está. O an-artista - diz ele - há de criar-se tendo como princípio a extinção da necessidade de sua existência. Ele disfarça-se de educador, compartilhando com todos ao seu redor as maneiras que ele pode conhecer de olhar a vida como obra de arte e, com isso, faz da função do artista (essa promoção de uma terapêutica social) uma desnecessidade.

Para que essa realidade se construa, ao mesmo tempo em que a apresenta efetiva, ele propõe, a partir da segunda metade da década de 1960, uma série de obras que carregam a presença-ausência como valor. Assim como a mãe que, entre os indispensáveis cuidados, precisa prover à criança uma solidão mais ou menos assistida, o artista oferece a possíveis colaboradores um roteiro mínimo - em que ele mesmo, enquanto forma, quase desaparece.

Negra rodovia pintada de preto

A chuva lava.

Homens de papel feitos em ramos de árvores nuas

A chuva lava.

Folhas escritas espalhadas pelo campo

A chuva lava ${ }^{5}$ (KAPROW, 1966, tradução livre).
4 .

Tradução livre do roteiro/ performance da artista fluxus Bici Forbes, composta em 1966 (FRIEDMAN, 2002): No original, lê-se: "Become invisible/a) by hiding/b) by divesting yourself of all distiguishing marks/c) by going away/d) by sinking through the floor/e) by becoming someone else/f) by concentrating so hard on some object or idea that you cease to be aware of your physical presence. $/ g$ ) by distracting everybody else from your physical presence/h) by ceasing to exist".

5

Tradução livre do trecho inicial do roteiro da atividade Raining, de Allan Kaprow, realizada em 1965 (KAPROW, 1966): No original: "Black highway painted Black/Rain washes away./Paper men made in bare orchard branches/ Rain washes away./Sheets of writing spread over a field/Rain washes away". 
Oculta-se o artista por trás de um recorrente gerúndio, que encontra como recurso para ampliar tanto quanto possível a possibilidade de escolha sobre a realização das ações por parte daqueles que com ele performatizam. Revela-se apenas como a voz que convida, como o chamado inevitável, como a mão do poeta que, sendo a poesia distinta de uma escrita tida como própria ao real, transparece no próprio fato da composição.

Realizando-se a ação, após os rituais de leitura e discussão do roteiro realizados em coletivo, temos então um processo em que as presenças dos colaboradores se expandem e contraem, em movimento de rítmica contínua - estão aqui e não estão, estão entre e para além de uma experiência dos afetos e da razão. Isso porque a execução dessas obras exige de seus participantes um duplo papel, em que eles se revezam entre uma dedicação meditativa - portanto atenta, mas detida, solitária - e a realização da ação, em momentos de interação e troca com outros participantes.

Sobre a dedicação meditativa, Bici Forbes recomenda, como estratégia para tornar-se invisível, que concentremo-nos tão fortemente em algo ou em alguma ideia a ponto de nossa presença física deixar de ser notada. O participante de uma dessas obras, porém, precisa integrar-se à ação, indo em sua direção mas também sem aderir a ela. A condição de possibilidade de uma participação presente-ausente é que se efetive a ação em sua concretude, mas sem deixar-se ser operado pela sua concreção. O participante mantém-se atento ao todo, sem deter-se em particularidades. Com a ajuda de François Jullien, tratando da possibilidade da "grande forma" na pintura:

No caso de o concreto "dominar" ou "reger", isso conduzirá à sua coisificação; ou se, correlativamente, o espírito se "fixasse" e se "focalizasse", se chegaria a uma lógica de apego e, em conseqüência, de sua exclusão6 (JULLIEN, 2008, p. 32, tradução livre).

Temos, então, a abertura ao outro: embora não estejamos jogando, mas simplesmente compartilhando nossa presença enquanto integramo-nos nesta vivência, é preciso que nos detenhamos em determinados pontos para que possamos, de acordo com o roteiro que foi por nós organizado, compartilhar as descobertas.

Encontro em algum lugar

Um conta em voz alta para ele/ela seu pulso

(observando contagem)

Outra vez...’ (KAPROW, 1966, tradução livre).
6.

No original: "Em el caso de que lo concreto 'dominara' y 'rigiera', ello conduzirá a sucoisificación; o si, correlativamente, elespiritu se 'fijara' y se 'focalizara', se llegaría a uma lógica de apego e, em consecuencia, de exclusión" (JULLIEN, 2008. p. 32).

Tradução livre de trecho do roteiro de atividade "Pulse Exchange", de 1973 (KAPROW, 1966): "Meeting somewhere/ One counting aloud his/her pulse for a minute/ (notingcount)/ Once again”. 
O participante apresenta-se, então, como heterotopia: um espelho que contém, em si, a minha - a mesma - e outra realidade - a deste meu colega, ou algo como ela. O reflexo me traz para o campo da razão por um momento - eu comparo dados, analiso números, mas não chego a ter, nesta interação, que me dedicar construtivamente ao outro. Logo em seguida, porém, a imersão é retomada por obra das indicações de ação - por obra do fazer, portanto.

Não julguemos de partida, porém - nestes tempos em que celebramos o coletivo - esta proposta de interação como pouco "relacional". Ela assim se constitui justamente por buscar dissolver também uma possibilidade de eu, de ego, de identidade. Não há nos roteiros a proposição de alteridades, de pontos de promoção ou defesa das diferenças. Todos são apenas um corpo, a priori: há um pulso, e ele é mais ou menos rápido em mim ou no outro, mas não é a diversidade das reações que se apresenta como questão quando eu estou vivendo o meu e o seu pulso. É, sim, a unidade da existência desse constante batimento e a realidade do afastamento que o cotidiano nos impõe, dessa nossa condição comum. Somos todos a existência desse pulso - que, como a presença, oscila: vai e vem.

Lembremo-nos, aqui, de que esse movimento de emergência e imersão é o mesmo proposto pelo filósofo americano pragmatista John Dewey para o processo de se vivenciar uma experiência (DEWEY, 2010) - o que inclui a experiência estética como aquela que constrói um conhecimento. Allan Kaprow, leitor de Dewey, transpõe para suas obras o movimento de fazer/padecer de seu mestre a partir de uma releitura que atribui a ela elementos muito distantes da proposta pragmatista, entendidos pelo ocidente como metafísicos - mas encarados pelo oriente puramente como ontológicos.

Há que se entender o velar-se, portanto, como uma propositiva conceitual na obra de Allan Kaprow: desaparecer-em-obra é (an-)arte. Lifework - obra de vida -, como pediria o artista. E é próprio do véu, matéria translúcida, o esconder sem fazêlo, o ocultar revelando. O véu: dispositivo possível para a presença-ausência.

Identificar a presença da ausência e seu valor nesses trabalhos que são historicamente prerrogativas para a performance contemporânea nos põe a repensar o valor constantemente atribuído à ideia de presença - uma ideia que, embora pouco precisa para quem produz exclusivamente teoria, ganhou um lugar de grande destaque nos discursos acerca da arte da performance. A presença sem ausência tende a conformar-se 
em identidade, podendo, assim, atrelar o performativo de forma inescapável à sua própria tautologia, sufocando a possibilidade da diferença, da variação, da respiração. Assim como o sábio, que "não se estanca em nenhum pensamento e preserva assim sua disponibilidade"8 (JULLIEN, 2008, p. 16, tradução livre), também ao performer é saudável manter-se em pulso, num fluxo presença-ausência - caso pretenda, evidentemente, alcançar um diálogo com o brilho que da "não forma" emana.

\section{Brincadeiras - para nutrir a vida}

\section{Música de jantar}

Um grupo de amigos comer um grande jantar. Depois, deitam-se. Eles põem microfones de contato em seus estômagos e, pelo próximo par de horas, ouvem os sons de sua digestão amplificados em um altofalantes que os circundam ${ }^{9}$ (KELLEY, 2004, p. 205, tradução livre).

Pela letra de Jeff Kelley (2004), curador e teórico da arte que acompanhou a obra de Allan Kaprow, podemos conhecer uma parcela dessa produção que a grande mídia não teve a oportunidade de cobrir - isso porque, já na década de 1980, o investimento de Kaprow em ocultar-se ou mesmo retirar-se do sistema de arte vinha obtendo alguns resultados. Com isso, eram poucos os convites e as encomendas de trabalhos por parte das galerias, apesar de todo o sucesso que haviam feito as obras dos anos anteriores, e assim o artista - que já vinha, desde meados da década de 1970, experimentando trabalhos progressivamente intimistas - passou a compor roteiros ainda mais privados, para duplas sem espectadores, para grupos muito pequenos, mas, especialmente, para que ele mesmo pudesse jogar/brincar junto aos seus amigos.

O campo da amizade foi se destacando pouco a pouco nas obras performativas de Kaprow, e na década de 1980 assumiu um posto definitivo, de muito valor. Desde o início de sua produção de obras que contavam com outras pessoas em ação, o trabalho com os happenings e as atividades serviu, para Kaprow, como uma boa desculpa para conhecer pessoas e fazer amigos (KELLEY, 2004). Nessas novas obras, porém, fazer amigos é explicitamente a motivação e o tema dessas peças.

De maneira diversa daquela dos trabalhos anteriores, portanto, as relações que se estabelecem entre pessoas nessas obras tardias não são aleatórias, superficiais e instrumentais. Nelas, pretende-se construir um espaço de intimidade fraterna, de uma alegria tão espontânea quanto possível.
8.

No original: "No se estanca em ningún pensamiento e preserva así su disponibilidade" (JULLIEN, 2008. p. 16).

9.

Tradução livre de "Dinner Music", de Allan Kaprow, proposta de 1981. No original: "Dinner music/ A group offriends eat a great dinner. Afterwards, they lie down to the rest. They put contact microphones on their bare stomachs and, for the next couple of hours, listen to their digestion sounds amplified on a surrounding loudspeakers" (KELLEY, 2004, p. 205). 
Para elaborar e propor suas experiências, Kaprow trabalhava sobre composições com os materiais da vida comum, diária, olhando jocosamente também para fatos e momentos que seriam normalmente tomados como desprezíveis. Entretanto, enquanto nas atividades essas ações ordinárias eram deslocadas para enquadramentos diferentes - ao modo do ready made, por sua própria "condição de obra", isto é, o agendamento de uma realização em determinado local que, a esta altura, já podia ser admitido como possível para a recepção de uma obra de arte - a moldura era exatamente a vida, o dia, as horas dos participantes.

Como renovar sua vida

Em sucessivos dias da semana, amigos rearranjam a mobília das casas uns dos outros. Afazeres diários prosseguem normalmente ${ }^{10}$ (KELLEY, 2004, p. 205, tradução livre).

Ao intensificar o caráter de divertimento, de gozo de seu próprio trabalho, e ao explorar ainda mais "materiais cotidianos", Allan Kaprow afastava-se mais e mais do sistema de arte, e já propunha mais vida que obra. O ato criativo e o engajamento na ação configuram, em sua obra, uma ação em prol da manutenção de uma existência sadia, jovial, um ato em busca da nutrição de sua própria vida - aqui entendida não biológica ou organicamente, mas como potência vital. Elaborar e participar de uma ação figuravam, para o artista, um exercício prático para a experiência de momentos que ampliassem sua capacidade de compreender a vida que ele era, e de levar adiante essa vida em sua potencialidade máxima - o que, certamente, não deve ser confundido com uma intensidade formal máxima.

A ideia de brincadeira havia sido, até então, e especialmente conforme ele elabora em "A educação do an-artista" (KAPROW, 1993), algo atrelado à representação, à emulação de situações e a fins didáticos. Imitava-se a vida - fora de contexto - para voltar à vida depois, com maior experiência para lidar com a própria situação que se havia emulado. Já aqui, brincar tem valor diverso. Pode-se fazer um paralelo entre a brincadeira infantil que chamamos hoje de "educativa" - uma brincadeira com fins externos, em que um adulto que a elabora e aplica tem a intenção de comunicar ou promover algum tipo de aprendizagem - e as atividades, contexto em que Kaprow, considerando nossa metáfora, assumiria o posto daquele educador bem intencionado. Por outro lado, a nova brincadeira a que o artista se propõe aproxima-se do brincar livre e desinteressado, o brincar não estruturado, exatamente aquele que o artista identificou em seu artigo como o mais sujo, o menos desejável por parte da sociedade de consumo estadunidense.
10.

Tradução livre de "How to renew your life", de Allan Kaprow, proposta de 1981: "How to renew your life / On sucessive days of a week, friends rearrange the furniture of each other's houses. Daily affairs continue normally" (KELLEY, 2004, p.205). 


\author{
Monkey business \\ Dois conhecidos passam juntos um dia ensolarado. Eles não falam. \\ Um segue o outro, caminhando na cabeça da sombra dele. \\ Às vezes, a cabeça da sombra está na frente, às vezes atrás. \\ Quando qualquer um sente que a distância entre eles é muito \\ pequena, ou muito grande, um sino é tocado ${ }^{11}$ (KELLEY, 2004, \\ p. 205, tradução livre).
}

Brincar desinteressadamente tem fim em si e, nessa dinâmica, por integrar o indivíduo de maneira total - não cindido entre corpo e mente -, tem o poder de alargar os modos de compreender que o circunda, nutrindo - concretamente, e não metaforicamente - a existência.

Nutrir a vida é uma propositiva que vem da antiga sabedoria chinesa, e que aqui observamos a partir do filósofo François Jullien, que busca colocá-la em contato com a cultura ocidental para que, nesse balanço, possamos encontrar algum proveito. Nas palavras do sinólogo,

Toda a vocação do meu ser, e minha única responsabilidade, está no cuidado que dedico a manter e efetivar esse potencial de vida do qual estou investido ${ }^{12}$ (JULLIEN, 2007, p. 15, tradução livre).

A consciência da arte da performance como brincadeira, e a necessidade que essa consciência impõe de que os artistas façam, ao modo de uma militância afetiva, a manutenção do distanciamento desta linguagem dos modos estritamente comerciais de produção e circulação das artes, está muito presente na produção (se é que podemos chamá-la assim) contemporânea. Multiplicam-se os espaços autogeridos ou "alternativos" de produção e exibição de obras. Do mesmo modo, amplia-se o número de espaços que permanentemente recebem artistas na qualidade de residentes, muitas vezes de maneira independente - isto é, sem que haja oferta de ajuda de custo ou cachê ao artista por parte do espaço, ou, ao contrário, cobrança de aluguel por uso criativo das dependências. E, ainda, festivais e mostras geridos de maneira não profissional, não comercial e não lucrativa ganham espaço e respeito, estabelecendo redes de muitos colaboradores e solidificando um circuito à parte daquele das galerias, salões e mostras oficiais.

Frequentando esse tipo de evento, percebe-se facilmente que muitos desses artistas que por ali circulam aproximam-se muito da "quase utopia" proposta por Kaprow pela figura do an-artista. Grande parte não possui formação acadêmica na área ou, quando possui, buscou na universidade uma possibilidade de imersão em sua produção, possibilidade facultada ou pela aura social que a academia emana para famílias provedoras ou pelas políticas de permanência das universidades públicas.
11.

Tradução livre de Monkey business, de Allan Kaprow, proposta de 1981. No original: "Monkey business / Two acquaintances spend $a$ sunny day together. They don't speak. One follows the other by walking on the head of the others shadow. Sometimes, the head of the shadow is in front, sometimes behind. When either one feels the distance between then is too close, or too far, a bell is sounded" (KELLEY, 2004, p. 205).

12.

Tradução livre de Jullien (2007) "Toda La vocación de mi ser, y mi única responsabilidade, está em el cuidado que dedico a mantener $y$ desplegar esse potencial de vida del que estoy investido". 
Muitos têm vidas profissionais que se fundamentam em outros setores, vidas paralelas, sem que isso configure algum tipo de frustração. A absoluta maioria desses artistas utiliza recursos próprios para participar desses eventos. Isso porque o que fazem ali, verdadeiramente, é divertir-se. É brincar uma brincadeira que lhes é vital. É fazer vida, é fazer-se, nutrindose. $E$, nesse sentido - na medida em que não trabalham pela reprodução da lógica do mercado - são an-artistas. Ao menos até que a próxima bienal os descubra.

\begin{abstract}
Somente quando desejarem cessar de ser artistas, os artistas ativos podem converter suas habilidades, como dólares em yens, em algo que o mundo possa gastar: jogar-brincar. Jogar-brincar como moeda. Podemos aprender melhor a jogar-brincar mediante exemplos, e an-artistas podem proporcionar isso. Em seu novo trabalho como educadores, eles precisam simplesmente jogar-brincar, como fizeram uma vez sob a bandeira da arte, mas em meio àqueles que não se importam com isso. Gradualmente, o pedigree "arte" se retrairá até tornar-se irrelevante (KAPROW, 1993, p. 184).
\end{abstract}

Estará a vida nesse pequeno circuito das atividades (quase não) artísticas, sendo nutrida em maior ou melhor grau que a vida, levada adiante quando estamos nas cidades, engajados em trabalhos e macbooks? Ou ainda, quais diferenças e semelhanças entre a vida, que nesse jogo se pode construir, e essa do outro polo, integralmente submetida ao regime? Estarão essas zonas autônomas temporárias - cujo caráter temporal se dá mais pela mobilidade constante daqueles que por ela passam do que por uma impermanência territorial - em posição privilegiada quanto ao processo de construção de uma sociedade mais plena? Acreditar nessas possibilidades é crer, junto a Kaprow, na arte mais despretensiosa como uma potência de transformação. Na arte "não engajada" como instrumento de revolução. É acreditar, portanto, na arte da performance e, especialmente, na possibilidade de construir a si mesmo a partir de uma relação lúdica com ela. 


\section{REFERÊNCIAS}

CLARK, Timothy J. Modernismos. São Paulo: Editora Cosac Naify, 2007.

DEWEY, John. Arte como Experiência. Tradução de Vera Ribeiro. São Paulo: Martins Fontes, 2010.

FRIEDMAN, Ken. The Fluxus Performance Workbook. 2002. Disponível em http://www.deluxxe.com/beat/fluxusworkbook. pdf Acesso em 15/05/2012.

JULLIEN, François. La granimagen no tiene forma. Barcelona: Alpha Decay, 2008.

François. Nutrir la vida - mas allá de la felicidade. Buenos Aires: Katz Editores, 2007.

KAPROW, Allan. The education of the Un-artist. In: KELLEY, Jeff (Org.). Essays on the blurring of art and life. Berkeley: University of California Press, 1993. pp. 50-103.

Some recent happenings. New York: Something Else Press, 1966.

. O legado de Jackson Pollock. In: COTRIM, Cecília e FERREIRA, Glória. (Orgs.) Escritos de artistas: anos 60/70. Tradução de Eliana Aguiar, Flávia Anderson, Pedro Süssekind et al. Rio de Janeiro: Jorge ZaharEditores, 2006. pp. 37-45.

KELLEY, Jeff. Childsplay: the art of Allan Kaprow. Berkeley: University of California Press, 2004.

KIRBY, Michael. The New Theatre. The Tulane Drama Review, vol. 10, n. 2 (inverno de 1965). pp. 23-43.

LYOTARD, Jean François. A condição pós-moderna. Rio de Janeiro: Edições Loyola, 1998. 